\title{
Acute effects of temperature and hypercarbia on cutaneous and branchial gas exchange in the South American lungfish, Lepidosiren paradoxa
}

\author{
Lucas A. Zena ${ }^{\mathrm{a}, \mathrm{b}, *}$, Kênia C. Bícego ${ }^{\mathrm{a}, \mathrm{b}}$, Glauber S.F. da Silva ${ }^{\mathrm{a}, \mathrm{b}}$, Humberto Giusti ${ }^{\mathrm{c}}$, \\ Mogens L. Glass ${ }^{\mathrm{c}}$, Adriana P. Sanchez ${ }^{\mathrm{d}}$ \\ a Department of Animal Morphology and Physiology, College of Agricultural and Veterinary Sciences, São Paulo State University, Jaboticabal, SP 14884- \\ 900 , Brazil \\ $\mathrm{b}$ National Institute of Science and Technology in Comparative Physiology (INCT Fisiologia Comparada), Brazil \\ ${ }^{\mathrm{c}}$ Department of Physiology, Faculty of Medicine of Ribeirão Preto, University of São Paulo, Ribeirão Preto, SP, Brazil \\ ${ }^{\mathrm{a}}$ Faculty of Health Sciences of Barretos Dr. Paulo Prata (FACISB), Barretos, SP, Brazil
}

\section{A R T I C L E I N F O}

\section{Keywords:}

Lungfish

$\mathrm{O}_{2}$ uptake

$\mathrm{CO}_{2}$ elimination

Dipnoi

\begin{abstract}
A B S T R A C T
The South American lungfish, Lepidosiren paradoxa inhabits seasonal environments in the Central Amazon and Paraná-Paraguay basins that undergo significant oscillations in temperature throughout the year. They rely on different gas exchange organs, such as gills and skin for aquatic gas exchange while their truly bilateral lungs are responsible for aerial gas exchange; however, there are no data available on the individual contributions of the skin and the gills to total aquatic gas exchange in L. paradoxa. Thus, in the present study we quantify the relative contributions of skin and gills on total aquatic gas exchange during warm $\left(35^{\circ} \mathrm{C}\right)$ and cold exposure $\left(20^{\circ} \mathrm{C}\right)$ in addition to the effects of aerial and aquatic hypercarbia on aquatic gas exchange and gill ventilation rate $\left(f_{G} ; 25^{\circ} \mathrm{C}\right)$, respectively. Elevated temperature $\left(35^{\circ} \mathrm{C}\right)$ caused a significant increase in the contribution of cutaneous (from $0.61 \pm 0.13$ to $1.34 \pm 0.26 \mathrm{ml}$. STPD. $\mathrm{h}^{-1} \mathrm{~kg}^{-1}$ ) and branchial (from $0.54 \pm 0.17$ to $1.73 \pm$ $0.53 \mathrm{ml}$. STPD. $\left.\mathrm{h}^{-1} \mathrm{~kg}^{-1}\right)$ gas exchange for $\dot{V} \mathrm{CO}_{2}$ relative to the lower temperature $\left(20^{\circ} \mathrm{C}\right)$, while $\dot{V} \mathrm{O}_{2}$ remained relatively unchanged. L. paradoxa exhibited a greater branchial contribution in relation to total aquatic gas exchange at lower temperatures $\left(20\right.$ and $\left.25^{\circ} \mathrm{C}\right)$ for oxygen uptake. Aerial hypercarbia decreased branchial $\dot{V} O_{2}$ whereas branchial $\dot{V} \mathrm{CO}_{2}$ was significantly increased. Progressive increases in aquatic hypercarbia did not affect $f_{G}$. This response is in contrast to increases in pulmonary ventilation that may offset any increase in arterial partial pressure of $\mathrm{CO}_{2}$ owing to $\mathrm{CO}_{2}$ loading through the animals' branchial surface. Thus, despite their reduced contribution to total gas exchange, cutaneous and branchial gas exchange in L. paradoxa can be significantly affected by temperature and aerial hypercarbia.
\end{abstract}

\section{Introduction}

The South American lungfish, Lepidosiren paradoxa, along with African (four species), and Australian lungfish (one species) are living representatives of the Dipnoi group (Carrol, 1987; Romer, 1970). Dipnoi is considered to be a sister-group to land vertebrates (Tetrapoda) (Brinkmann et al., 2004a, 2004b; Meyer and Zardoya, 2003; Tohyama et al., 2000; Zardoya et al., 1998) and, thus, is an important group regarding the transition from aquatic to air-breathing.

South American lungfish inhabit temporary hydric systems like the Central Amazon and Paraná-Paraguay basins (Paraná, Paraguay and Amazon Rivers), and they experience changes in environmental gases due to high rates of organic vegetal decomposition in temporary lakes
(Chellappa et al., 2005; Neiff, et al., 2009). They also experience phases of dryness (aestivation during dry winters); changes in water $\mathrm{pH}$ (ranging from 6.5 to nearly 9.0); and large temperature oscillations (18-34 ${ }^{\circ} \mathrm{C}$ ) (Harder et al., 1999; da Silva et al., 2013) with the highest temperatures recorded mainly between September and December (Chellappa et al., 2005).

All living species of lungfishes (Lepidosirenidae, Protopteridae and Ceratodontidae) show both aquatic and aerial respiration (Amin-Naves et al., 2004; Burggren and Johansen, 1986; Graham, 1997; Johansen, et al., 1967; Johansen and Lenfant, 1968; McMahon, 1970) with the predominant role of gas exchange organs varying among species and throughout development (de Moraes et al., 2005; Johansen and Lenfant, 1967; Babiker, 1979; Perry, et al., 2005). While pulmonary

\footnotetext{
* Correspondence to: Departamento de Morfologia e Fisiologia Animal, Faculdade de Ciências Agrárias e Veterinárias, Universidade Estadual Paulista Júlio de Mesquita Filho, Via de acesso Paulo Donato Castellane s/n, 14884-900, Jaboticabal, SP, Brazil.

E-mail addresses: lucaszena@gmail.com, lucaszena@yahoo.com.br (L.A. Zena).
} 
(aerial) gas exchange has been preferentially examined in lungfishes (Amin-Naves et al., 2004; Johansen and Lenfant, 1967, 1968), skin-gill (aquatic) gas exchange contributions have gained less attention probably because branchial surface area in full-grown animals is reduced and may not be enough to provide adequate oxygen supply to the whole organism especially during high metabolic demands imposed by high temperature challenges (de Moraes et al., 2005; Amin-Naves et al., 2004). Few studies have compared the roles of aerial and aquatic respiratory gas exchange in lungfish (Amin-Naves et al., 2004; Babiker, 1979; Johansen et al., 1976; McMahon, 1970; Perry et al., 2005). Studies in L. paradoxa have assessed the role of aerial and total aquatic gas exchanges at different temperatures and demonstrated that $L$. paradoxa is capable of increasing oxygen consumption at high temperature $\left(35^{\circ} \mathrm{C}\right)$ relying mainly on their lungs (Amin-Naves et al., 2004). In addition, combined hypercarbia, i.e. in the air and aquatic phases, evokes acid-base perturbations that are defended by large and transient increases in pulmonary ventilation in L. paradoxa (Sanchez and Glass, 2001; Sanchez et al., 2005).

Besides studies that have emphasized the primary role of the lungs in total gas exchange, morphometric measurements of all gas exchange organs (lungs, skin and gills) in L. paradoxa have found that the skin is a potentially important respiratory surface for $\mathrm{CO}_{2}$ elimination, and the gills have a negligible role for oxygen uptake (de Moraes, et al., 2005). However, no studies have quantified the partitioning of aquatic gas exchange between skin and gills nor investigated their possible differential control facing acute warm and cold exposure or high $\mathrm{CO}_{2}$ levels that may alter cutaneous and branchial gas exchange. Therefore, we quantified the relative contributions of skin and gills to total aquatic gas exchange of adult specimens of the South American lungfish, Lepidosiren paradoxa, at different acute temperatures $(20,25$ or $35^{\circ} \mathrm{C}$ ) and during exposure to aerial hypercarbia at $25^{\circ} \mathrm{C}$.

\section{Material and methods}

\subsection{Animals}

Specimens of Lepidosiren paradoxa Fitzinger $1837(585 \pm 28 \mathrm{~g}$ body weight; $N=9$ ) were collected in the region of the Pantanal close to Cuiabá, Mato Grosso, Brazil. Animals were transported to the University of São Paulo, Ribeirão Preto, São Paulo State, where they were kept in $250 \mathrm{l}$ tanks containing PVC tubes for hiding and filled with de-chlorinated tap water under constant temperature $\left(25^{\circ} \mathrm{C}\right)$. They were fed to satiety with chicken liver three times a week; food was withheld at least $48 \mathrm{~h}$ before surgeries and experiments. All experimental protocols were carried out during the animals' active season (September 2005 to April 2006). Animal collection was approved by the environmental agency SISBIO/IBAMA (Instituto Brasileiro do Meio Ambiente e Recursos Naturais Renováveis/IBAMA/MMA - ${ }^{\circ}$ 02027.0021722005-68 and $\mathrm{n}^{\circ}$ 46160-1), and animal use was approved by the Ethics Committee of University of São Paulo, Faculty of Medicine of Ribeirão Preto (CETEA - Process \#1712005).

\subsection{Surgeries}

Animals were anaesthetized by immersion in benzocaine solution $\left(1 \mathrm{~g} \mathrm{~L}^{-1}\right)$ for $10 \mathrm{~min}$ until postural reflexes disappeared. To partition measurements of aquatic gas exchange an elastic ring (65\% polyester and $35 \%$ elastodien) of variable diameter (dependent on the animal's size) and $15 \mathrm{~mm}$ of width was sutured in place behind the gills. A ring made of a vinyl glove cuff was sutured to the elastic to create a septum that filled the entire diameter of the recording chamber partitioning the head from the rest of the body (Fig. 1). After this procedure, lungfishes were returned to water at $25{ }^{\circ} \mathrm{C}$ and allowed to recover from the anesthesia for one hour. All experiments were performed in unanesthetized animals $>24 \mathrm{~h}$ after the surgical procedure.

The elastic ring was removed after the experiments for partitioning
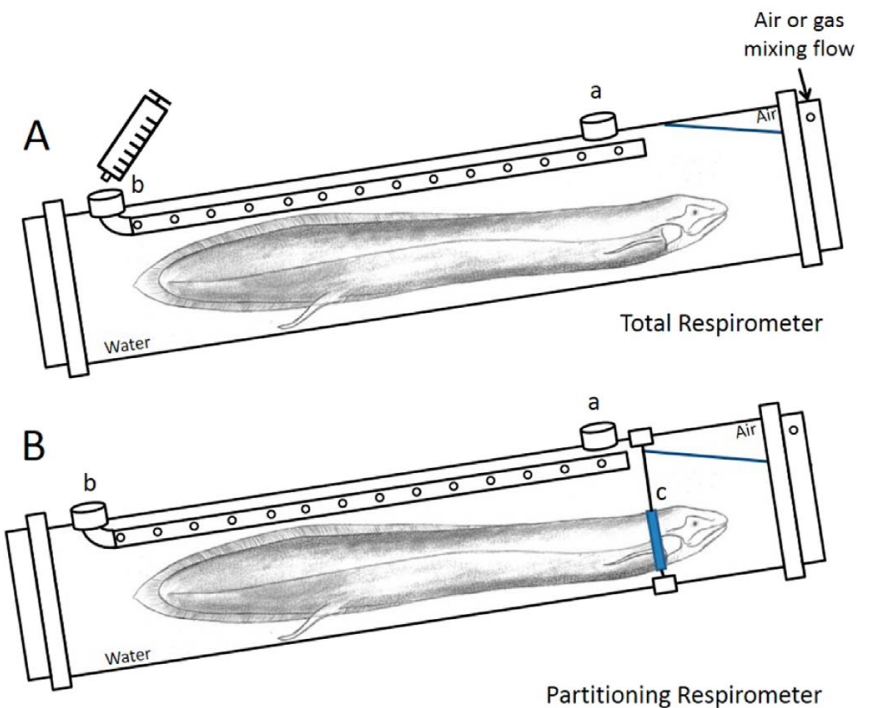

Fig. 1. Drawings of experimental apparatus (respirometer) constructed with a PVC tube show how aquatic and aerial gas exchange was measured. A. A total respirometer was used to measure whole body gas exchange (gills + skin); B. A partitioning respirometer was used to measure skin gas exchange. In A and $\mathrm{B}, a$ and $b$ represent holes in PVC tube for respirometer water renewal. $b$ also represents the hole for water samples to quantify $\mathrm{P}_{\mathrm{w}} \mathrm{O}_{2}$ and $\mathrm{P}_{\mathrm{w}} \mathrm{CO}_{2} . c$ represents the combination between an elastic and a vinyl ring (a septum) sutured to the animal skin just caudal to the gills openings (for details see material and methods). Source: Drawn by L.A. Zena.

of aquatic gas exchange, and animals were allowed to recovery from the above-mentioned procedures for at least one month. A group of six animals were again anaesthetized (as described above), and a polyethylene cannula (PE-50; Clay Adams, Parsippany, NJ, USA) filled with water was inserted into the right gill opening and sutured in place for gill ventilation rate $\left(f_{G}\right)$ measurements. Gill ventilation experiments were performed $>24 \mathrm{~h}$ after the cannula insertion.

\subsection{Measurements of gas exchange and gill ventilation rate}

Partial pressure of oxygen in water $\left(\mathrm{P}_{\mathrm{w}} \mathrm{O}_{2}\right)$ was analyzed with $\mathrm{O}_{2}$ electrodes (FAC Instruments, São Carlos, SP, Brazil) connected to an $\mathrm{O}_{2}$ analyzer (FAC 204 A; FAC Instruments, São Carlos, SP, Brazil). The electrodes were calibrated using water equilibrated with pure $\mathrm{N}_{2}$ and with room air. Partial pressure of $\mathrm{CO}_{2}$ in water $\left(\mathrm{P}_{\mathrm{w}} \mathrm{CO}_{2}\right)$ was measured by a $\mathrm{CO}_{2}$ electrode (BGM 200-Cameron Instruments, Port Aransas, TX, USA) calibrated with $3 \%$ and $6 \% \mathrm{CO}_{2}$ in $21 \% \mathrm{O}_{2}$ and balance $\mathrm{N}_{2}$ in the gas mixture using a gas mixing flowmeter (GF-3/MP, Cameron Instrument, Port Aransas, TX, USA). Electrodes were calibrated and maintained at specific temperatures of the experimental procedures $\left(20,25\right.$, and $\left.35^{\circ} \mathrm{C}\right)$. Oxygen uptake from the water $\left(\dot{V} O_{2}\right)$ was measured as the decrease of $\mathrm{O}_{2}\left(\mathrm{P}_{\mathrm{w}} \mathrm{O}_{2}\right.$ initial $-\mathrm{P}_{\mathrm{w}} \mathrm{O}_{2}$ final $)$ :

$$
\begin{aligned}
\text { Aquatic } \dot{V} O_{2}\left(m L . S T P D . h^{-1} \mathrm{~kg}^{-1}\right) & =V_{\text {tot }} . \\
\alpha O_{2} & \times \frac{P_{w} O_{2} \text { initial }-P_{w} O_{2} \text { final }}{\Delta \text { time } \times \text { bodymass }}
\end{aligned}
$$

where $V_{\text {tot }}=$ total water volume in the experimental apparatus; $\alpha_{2} \mathrm{O}_{2}=$ solubility of $\mathrm{O}_{2}$ in distilled water (Dejours, 1981); $\mathrm{P}_{\mathrm{w}} \mathrm{O}_{2}$ initial $-\mathrm{P}_{\mathrm{w}} \mathrm{O}_{2}$ final $=$ difference in final $\mathrm{O}_{2}$ partial pressure in relation to the initial values; $\Delta$ time $=$ time difference between final and initial reading.

Carbon dioxide elimination $\left(\dot{V} \mathrm{CO}_{2}\right)$ was calculated $\left(\mathrm{P}_{\mathrm{w}} \mathrm{CO}_{2}\right.$ final $\mathrm{P}_{\mathrm{w}} \mathrm{CO}_{2}$ initial) as:

$$
\begin{array}{r}
\text { Aquatic } \dot{\mathrm{V} C \mathrm{O}_{2}\left(\mathrm{~mL} . \mathrm{STPD} . \mathrm{h}^{-1} \mathrm{~kg}^{-1}\right)}=\mathrm{V}_{\text {tot }} . \alpha \mathrm{CO}_{2} \times \\
\frac{P_{w} \mathrm{CO}_{2} \text { final }}{\Delta \text { time } \times \text { bodymass }}
\end{array}
$$

where $\alpha \mathrm{CO}_{2}=$ solubility of $\mathrm{CO}_{2}$ in distilled water; $\mathrm{P}_{\mathrm{w}} \mathrm{CO}_{2}$ final $-\mathrm{P}_{\mathrm{w}} \mathrm{CO}_{2}$ 
initial $=$ difference in final partial pressure of $\mathrm{CO}_{2}$ in relation to the initial values; $\Delta$ time $=$ time difference between final and initial reading. All values for $\dot{V} \mathrm{O}_{2}$ and $\dot{V} \mathrm{CO}_{2}$ are expressed as mass-specific, i.e. ml. STPD. $\mathrm{h}^{-1} \mathrm{~kg}^{-1}$.

Gill ventilation rate was obtained using a pressure transducer (MLTO380/D, ADInstruments, Sydney, Australia) connected to a catheter implanted in the animal's right gill opening. The pressure signals were recorded with a data acquisition system (MML110 Power Lab, ADInstruments, Sydney, Australia) and analyzed using Labchart software (PowerLab, ADInstruments, Sydney, Australia).

\subsection{Experimental protocols}

\subsubsection{Aquatic gas exchange}

On the day of the experiment, an unanaesthetized, intact lungfish was placed in an aquarium with dechlorinated water and exposed to a specific temperature $\left(20,25\right.$ or $\left.35^{\circ} \mathrm{C}\right)$ for one hour. Different temperatures were performed with at least a $24 \mathrm{~h}$ interval between challenges. After this period, the animal was transferred to the experimental apparatus (respirometer) constructed with a PVC tube containing water equilibrated with room air at the same temperature to which it had been exposed in the temperature challenge. The tube was maintained slightly inclined in an aquarium with dechlorinated water (Fig. 1A), permitting adequate movement for voluntary aerial respiration. The experimental apparatus had two holes (anterior and posterior, see Fig. 1A) to permit flushing of fresh water and to take water samples for analysis with $\mathrm{O}_{2}$ and $\mathrm{CO}_{2}$ electrodes. Water samples were extracted from the respirometer with a $1 \mathrm{ml}$ syringe connected to a perforated catheter extending along the PVC tube (Fig. 1A). Water control samples $(1 \mathrm{ml})$ were extracted immediately after the animal transference to the experimental apparatus (initial reading) and one additional water sample was obtained two hours later (final reading).

\subsubsection{Skin gas exchange}

This protocol was designed to quantify the skin's contribution in the total aquatic gas exchange. To this end, one day after combined elastic and vinyl glove ring (the septum) attachment to the animal's skin, the lungfish was transferred to the experimental apparatus (partitioning respirometer; Fig. 1B) at the same temperature to which it was exposed in the temperature challenge $\left(20,25\right.$ or $\left.35^{\circ} \mathrm{C}\right)$. In this apparatus the region posterior to the gills was inserted into the PVC tube so that the water surrounding the animal's head was separated from the water surrounding its body by the septum into another extension of the PVC tube (Fig. 1B). This septum did not prevent the animal's voluntary movement to breathe air. Water samples were extracted from the respirometer with a $1 \mathrm{ml}$ syringe connected to a perforated catheter extending along the PVC tube (Fig. 1B). Control water samples (1 ml) were extracted immediately after the animal's transference to the experimental apparatus (initial reading) and the additional samples were obtained two hours later (final reading). By subtracting the skin gas exchange (Fig. 1B) from total aquatic gas exchange (described above; Fig. 1A) it was possible to estimate branchial contribution of total aquatic gas exchange.

\subsubsection{Aquatic gas exchange during aerial hypercarbia}

Aquatic gas exchange during aerial hypercarbia $\left(5 \% \mathrm{CO}_{2}\right.$ in $21 \% \mathrm{O}_{2}$ and balance $\mathrm{N}_{2}$ ) at $25{ }^{\circ} \mathrm{C}$ was measured after aerial normocarbia at $25{ }^{\circ} \mathrm{C}$ for both protocols 2.4.1 and 2.4.2 where partitioning of cutaneous and branchial gas exchange $\left(\dot{V} \mathrm{O}_{2}\right.$ and $\left.\dot{V} \mathrm{CO}_{2}\right)$ were repeated during aerial hypercarbia through two-hours of exposure after which a final water sample $(1 \mathrm{ml})$ was obtained and compared to the initial water sample taken at the beginning of the experiment.

\subsubsection{Gill ventilation rate under aquatic normocarbia and hypercarbia}

One month after experiments performed for aquatic gas exchange measurements (protocols 2.4.1; 2.4.2 and 2.4.3) in which the vinyl glove ring had already been removed and the animal had fully recovered from the previous experimental protocol (aquatic gas exchange), a group of six intact $L$. paradoxa had gill ventilation rate measured under aquatic normocarbia followed by serial increases in hypercarbia. After the surgical procedure for catheter implantation into the right gill opening, animals were maintained for $24 \mathrm{~h}$ in a rectangular glass chamber $\left(40 \mathrm{~cm} \times 20 \mathrm{~cm} \times 22 \mathrm{~cm}\right.$ ) filled with water (at $25^{\circ} \mathrm{C}$; no PVC tube) before starting the experiments. Subsequent experiments were performed in the glass chamber which had its four corners bubbled with room air (using four aquarium aerators) with a flow rate of $5000 \mathrm{ml} \mathrm{min}^{-1}$ split between the four aerators for the first $30 \mathrm{~min}$. Then the water was bubbled with serial increasing hypercarbic mixtures $\left(0.5 \%, 1.0 \%, 3.0 \%\right.$ and $5.0 \% \mathrm{CO}_{2}$ in $21 \% \mathrm{O}_{2}$ and $\mathrm{N}_{2}$ balance), at the same flow rate $\left(5000 \mathrm{ml} \mathrm{min}^{-1}\right)$, lasting $30 \mathrm{~min}$ per mixture. At the end of each normocarbic and hypercarbic exposure, a water sample was analyzed with a $\mathrm{PCO}_{2}$ electrode to ensure that equilibrium was reached. Gill ventilation rate was recorded throughout the $30 \mathrm{~min}$ period for each condition.

\subsection{Statistics}

Results are presented as means \pm S.E.M. Statistical analysis was performed using a two-way ANOVA (factors: respiratory organ $\times$ temperature or hypercarbia). A one-way RM ANOVA was used to analyze the effect of graded aquatic hypercarbia on gill ventilation rate. Whenever an ANOVA resulted in significant main or interaction effects, a Holm-Šidák post hoc test was performed to identify the differences. Data were tested for unequal variance and normality, and a log transformation was carried out when necessary. Data for relative contribution of skin and gill gas exchange (percentage data) for total $\dot{V} \mathrm{O}_{2}$ and $\dot{V} \mathrm{CO}_{2}$ were calculated as proportions, and an arcsin-square root transformation was applied for subsequent ANOVA analysis. Significance levels were accepted where $P<0.05$.

\section{Results}

\subsection{Aquatic gas exchange at different temperatures}

Aquatic $\mathrm{O}_{2}$ uptake and $\mathrm{CO}_{2}$ excretion of L. paradoxa through the skin and gills are shown in Fig. 2. Acute changes in temperature did not modify gas exchange for either the cutaneous or branchial $\dot{V} O_{2}$ (Fig. 2A and B). In contrast, cutaneous and branchial $\dot{V} \mathrm{CO}_{2}$ were significantly affected by temperature $\left(P=0.002 ; \mathrm{F}_{2,48}=7.391\right)$ where a decrease from 25 to $20^{\circ} \mathrm{C}$ did not affect cutaneous $\dot{V} \mathrm{CO}_{2}$ significantly $\left(20^{\circ} \mathrm{C}\right.$ : $0.61 \pm$ 0.13 vs. $25^{\circ} \mathrm{C}$ : $0.60 \pm 0.10 \mathrm{ml}$. STPD. ${ }^{-1} \mathrm{~kg}^{-1}$; Fig. 2B), while an increase from 25 to $35^{\circ} \mathrm{C}$ augmented cutaneous $\dot{V} \mathrm{CO}_{2}$ by $123 \%$ $\left(25^{\circ} \mathrm{C}: 0.60 \pm 0.10\right.$ vs. $35^{\circ} \mathrm{C}: 1.34 \pm 0.26 \mathrm{ml}$. STPD.h ${ }^{-1} \mathrm{~kg}^{-1}$; Fig. $\left.2 \mathrm{~B}\right)$. Branchial $\dot{V} \mathrm{CO}_{2}$ exhibited a decrease of $80 \%$ when cooled from 25 to $20{ }^{\circ} \mathrm{C}\left(20^{\circ} \mathrm{C}\right.$ : $0.54 \pm 0.17$ vs. $25^{\circ} \mathrm{C}: 0.98 \pm 0.21 \mathrm{ml}$. STPD. $\mathrm{h}^{-1} \mathrm{~kg}^{-1}$; Fig. 2B), while acute exposure to $35^{\circ} \mathrm{C}$ elevated $\dot{V} C_{2} 80 \%\left(25^{\circ} \mathrm{C}: 0.98\right.$ \pm 0.21 vs. $35^{\circ} \mathrm{C}: 1.73 \pm 0.53 \mathrm{ml}$. STPD. $\mathrm{h}^{-1} \mathrm{~kg}^{-1}$; Fig. 2B). There was no difference between cutaneous and branchial $\mathrm{O}_{2}$-uptake $(P=0.23)$ and $\mathrm{CO}_{2}$ production $(P=0.42)$ nor interaction between factors for both $\dot{V} O_{2}$ and $\dot{V} \mathrm{CO}_{2}$ across temperatures ( $P=0.06$ and 0.30 , respectively).

Owing to the absence of differences for $\dot{V} \mathrm{O}_{2}$ and $\dot{V} \mathrm{CO}_{2}$ between skin and gills within each temperature (Fig. 2), we calculated cutaneous and branchial $\dot{V} \mathrm{O}_{2}$ and $\dot{V} \mathrm{CO}_{2}$ as a percentage of the total aquatic gas exchange in order to distinguish the relative contribution between gas exchange organs, cutaneous and branchial, at $25^{\circ} \mathrm{C}$ and during exposure to low $\left(20^{\circ} \mathrm{C}\right)$ and high $\left(35^{\circ} \mathrm{C}\right)$ temperatures (Fig. 3; see Amin-Naves et al., 2004). Gills contributed more than skin to $\dot{V} O_{2}$ at lower temperatures, 20 and $25{ }^{\circ} \mathrm{C}$ (interaction effect: $P<0.05 ; \mathrm{F}_{2,47}$ $=5.282$ ). In contrast, regardless of temperature, there were no differences in the contributions to $\dot{V} C O_{2}$ of gills and skin ( $P=0.63$; Fig. $\left.3 \mathrm{~B}\right)$, i.e. they equally contributed to aquatic $\mathrm{CO}_{2}$ excretion. $\mathrm{CO}_{2}$ was fourfold 

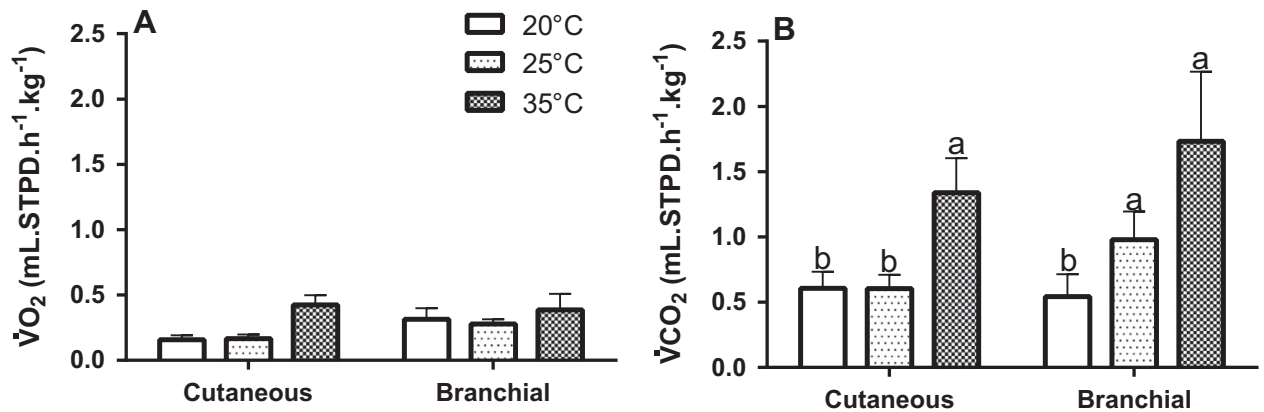

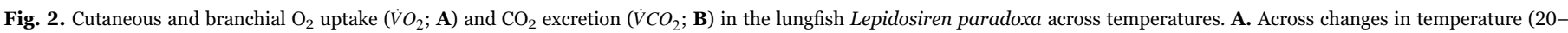

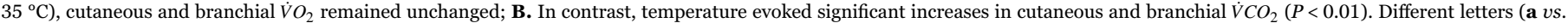
b) mean significant effect of temperature within cutaneous or branchial $(P<0.05$; Holm-Šidák post hoc test). Data are means \pm S.E.M. $N=8-9$ animals.
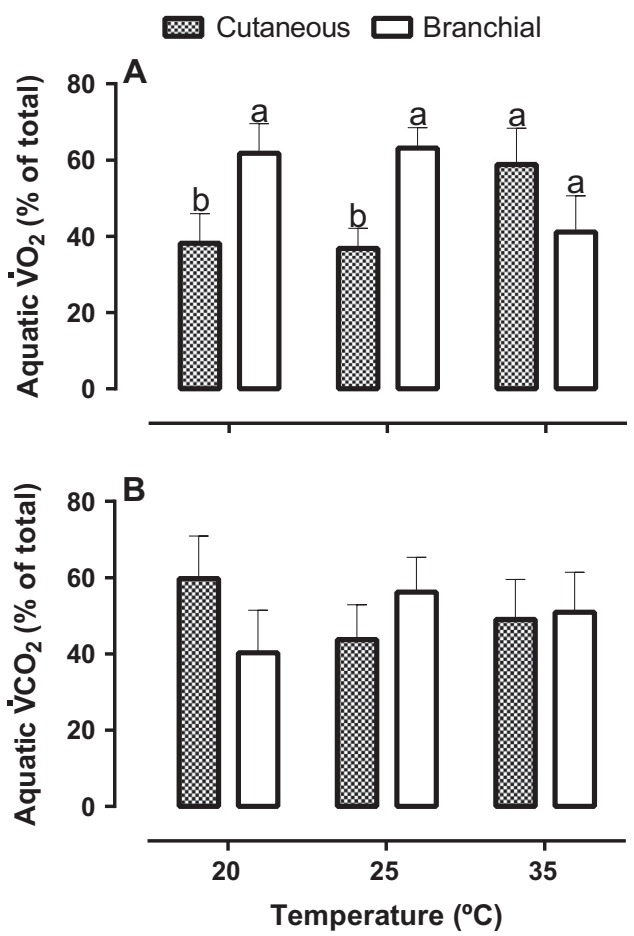

Fig. 3. Relative contribution to aquatic $\mathrm{O}_{2}\left(\dot{V} \mathrm{O}_{2} ; \mathbf{A}\right)$ and $\mathrm{CO}_{2}\left(\dot{V} \mathrm{CO}_{2} ; \mathbf{B}\right)$ gas exchange through the skin and gills across temperature in the lungfish Lepidosiren paradoxa. A. Effect of temperature in the aquatic $\dot{V} O_{2}$ contribution from skin and gills as a percentage relative to total aquatic gas exchange; B. Effect of temperature in the aquatic $\dot{V} \mathrm{CO}_{2}$ contribution from skin and gills as a percentage relative to total aquatic gas exchange. Different letters (a $v s . \mathbf{b})$ mean significant effect of branchial over cutaneous gas exchange within each temperature $(P<0.05 ;$ Holm-Šidák post hoc test). Data are means \pm S.E.M. $N=8-9$ animals.

higher than $\mathrm{O}_{2}$, as expressed by the respiratory exchange ratio $\left(\dot{V} \mathrm{CO}_{2} / \dot{V} \mathrm{O}_{2}\right)$ for aquatic gas exchange for skin $(3.9 \pm 0.5)$ and gills $(4.1 \pm 0.75)$, and aquatic respiratory exchange ratio did not change with acute changes in temperature ( $P=0.98$; Fig. 4$)$.

\subsection{Aquatic gas exchange during aerial hypercarbia at $25^{\circ} \mathrm{C}$}

Aquatic $\dot{V} \mathrm{O}_{2}$ and $\dot{V} \mathrm{CO}_{2}$ responses were measured during hypercarbia in the gas phase (Fig. 5). Hypercarbia did not change cutaneous $\mathrm{O}_{2}$ uptake, but it decreased branchial $\dot{V} O_{2}$ from $0.44 \pm 0.05 \mathrm{ml}$. STPD. ${ }^{-1} \mathrm{~kg}^{-1}$ (normocarbia) to $0.06 \pm 0.06 \mathrm{ml}$. STPD. ${ }^{-1} \mathrm{~kg}^{-1}$ (interaction effect: $P<0.001, \mathrm{~F}_{1,34}=23.940$; Fig. 5A). Hypercarbia caused an increase in branchial $\dot{V} C O_{2}\left(P<0.05 ; \mathrm{F}_{1,34}=5.036\right.$; Fig. 5B $)$, but did not change cutaneous $\mathrm{CO}_{2}$ excretion. $\mathrm{CO}_{2}$ excretion was significantly higher across the branchial surface compared with the cutaneous surface $(P<$ $0.01 ; \mathrm{F}_{1,34}=9.446$; Fig. $5 \mathrm{~B}$ ) during hypercarbia (skin: $0.85 \pm 0.23$ vs.

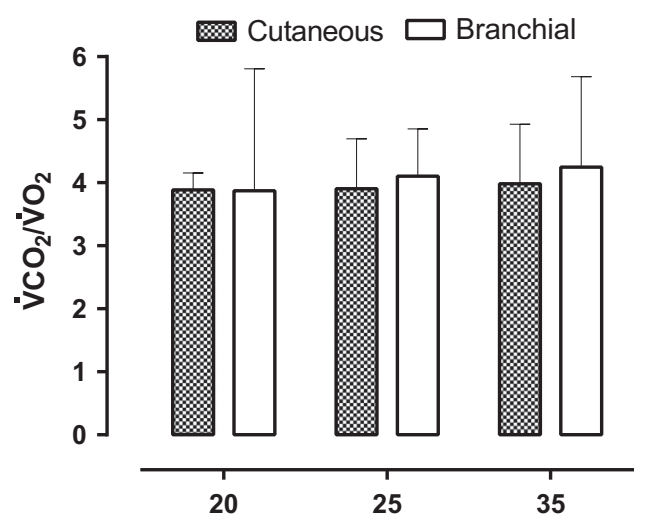

Fig. 4. Cutaneous and branchial gas exchange ratio $\left(\dot{V} \mathrm{CO}_{2} / \dot{V} \mathrm{O}_{2}\right)$ in the lungfish Lepidosiren paradoxa across temperatures. Besides no changes in the gas exchange ratio across temperature or between aquatic respiratory organs, L. paradoxa exhibits high values for the $\dot{V} \mathrm{CO}_{2} / \dot{V} \mathrm{O}_{2}$ relationship ( 4.0) meaning that large amounts of $\mathrm{CO}_{2}$ are eliminated by both cutaneous and branchial gas exchangers. Data are means \pm S.E.M. $N$ $=7-9$ animals.

branchial: $1.9 \pm 0.33 \mathrm{ml}$. STPD $\cdot \mathrm{h}^{-1} \mathrm{~kg}^{-1}$ ).

\subsection{Gill ventilation rate during aquatic hypercarbia at $25{ }^{\circ} \mathrm{C}$}

Gill ventilation rate was $1.0 \pm 0.2$ breath $\mathrm{min}^{-1}$ in normocarbia. Gradual increases in aquatic partial pressure of $\mathrm{CO}_{2}$ did not significantly affect this variable in $L$. paradoxa, compared with the normocarbic condition (Fig. 6).

\section{Discussion}

The present study describes the contributions of branchial and cutaneous $\mathrm{O}_{2}$ and $\mathrm{CO}_{2}$ gas exchange to aquatic respiration of $L$. paradoxa. We report for the first time in adult specimens of South American lungfish an estimation of contributions for each component involved in the aquatic gas exchange, i.e. skin and gills, and we describe how acute changes in temperature and hypercarbia affect them. Temperature affected metabolic rate of lungfishes whereby $\mathrm{CO}_{2}$ excretion from branchial tissue decreased and increased during acute reduction $\left(20^{\circ} \mathrm{C}\right)$ and elevation $\left(35^{\circ} \mathrm{C}\right)$ in temperature, respectively, in contrast to no thermal effect on cutaneous and branchial $\dot{V} O_{2}$ (Fig. 2). Regardless of changes in temperature, the gills and skin of L. paradoxa relative contributions remained about the same for aquatic $\dot{V} \mathrm{CO}_{2}$, and conversely, gills exhibited a relative higher percent contribution compared to cutaneous aquatic $\dot{V} O_{2}$ at $25^{\circ} \mathrm{C}$ and when exposed to $20^{\circ} \mathrm{C}$, but not $35^{\circ} \mathrm{C}$ (Fig. 3).

The predominance of a particular type of breathing - aquatic or aerial - is related, among other factors, to the respiratory organ surface area (Hughes, 1980) which varies among species and developmental 

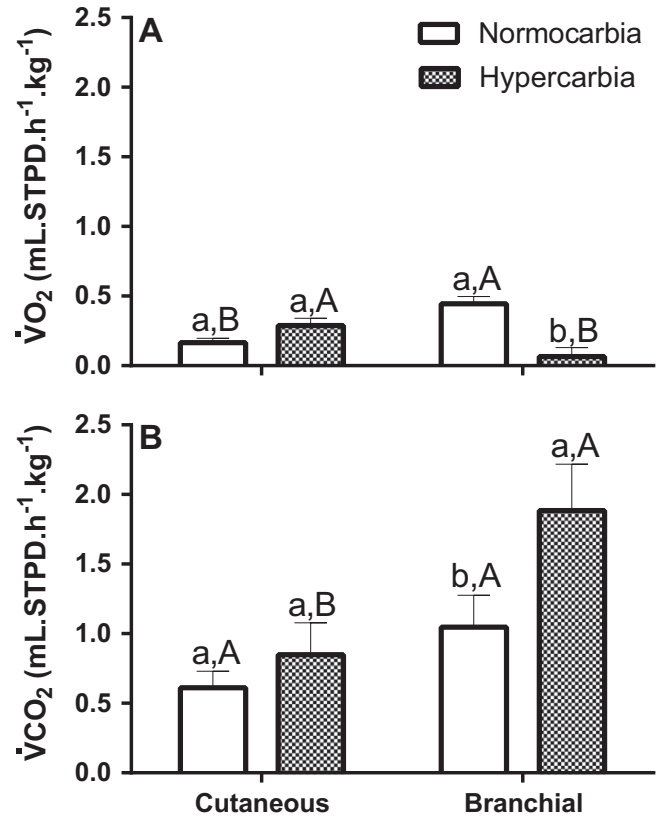

Fig. 5. Cutaneous and branchial $\mathrm{O}_{2}$ uptake $\left(\dot{V} \mathrm{O}_{2} ; \mathbf{A}\right)$ and $\mathrm{CO}_{2}$ excretion $\left(\dot{V} \mathrm{CO}_{2} ; \mathbf{B}\right)$ in the lungfish Lepidosiren paradoxa, at $25^{\circ} \mathrm{C}$, during aerial normocarbia and hypercarbia ( $5 \%$ $\mathrm{CO}_{2}$ ). A. Effect of aerial normocarbia and hypercarbia on cutaneous and branchial $\dot{V} \mathrm{O}_{2}$. B. Effect of aerial normocarbia and hypercarbia on cutaneous and branchial $\dot{V} \mathrm{CO}_{2}$. Different lowercase letters (a vs.b) mean significant effect of hypercarbia within cutaneous or branchial, and different capital letters (A $v s . \mathbf{B})$ mean significant difference between cutaneous and branchial within normocarbia or hypercarbia $(P<0.05$; HolmŠidák post hoc test). Data are means \pm S.E.M. $N=9$ animals.

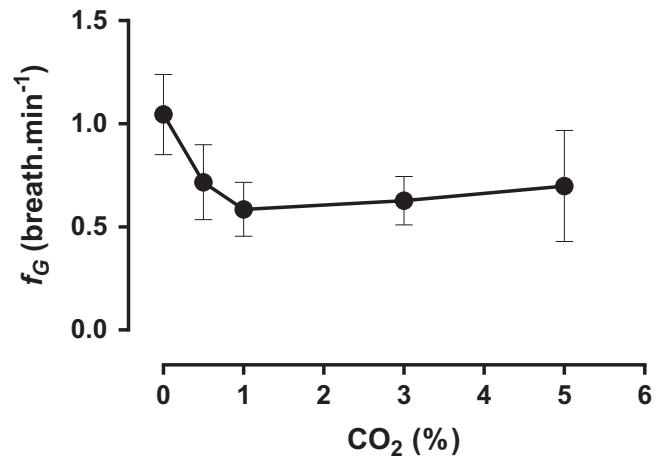

Fig. 6. Effect of increasing levels of aquatic hypercarbia on gill ventilation rate $\left(f_{G}\right)$ in the lungfish Lepidosiren paradoxa. Although there appears to be a trend of decreasing $f_{G}$ during $1 \%$ exposure to high aquatic $\mathrm{CO}_{2}$, L. paradoxa maintained $f_{G}$ relatively constant across all levels of aquatic hypercarbia (no significant differences). $N=6$ animals.

stages (McMahon, 1970). African lungfishes, for example, possess true lungs, and gills are also present permitting bimodal breathing (reviewed by Burggren and Johansen, 1986). For instance, i) high branchial ventilation occurs in juvenile Protopterus annectens, but in mature fishes $(>400 \mathrm{~g}) 80-85 \%$ of $\mathrm{O}_{2}$-uptake occurs in the lungs (Babiker, 1979); ii) in adult Protopterus dolloi, approximately 9\% of $\mathrm{O}_{2}$ uptake and $24 \%$ of $\mathrm{CO}_{2}$ excretion are aquatic (skin and gills) (Perry et al., 2005); iii) in Protopterus amphibius, the juvenile fishes are able to supply $70 \%$ of $\mathrm{O}_{2}$-uptake by their aquatic breathing route compared with only $10-15 \%$ in older fishes that also exhibit external gills (Johansen et al., 1976); and iv) in adults P. aethiopicus, $60 \%$ of $\mathrm{CO}_{2}$ excretion is aquatic (gills) while $90 \%$ of oxygen consumption is acquired by the lungs (McMahon, 1970).

In the South American lungfish the gills are important organs for aquatic gas exchange during larval and juvenile phases (Babiker, 1979; Johansen et al., 1976; Kerr, 1899). L. paradoxa embryos hatch with 4 large pairs of gill arches that continue to grow in length. About six weeks after hatching, the larvae undergo changes, and their circulation to the external gills becomes sluggish which then start to regress (Kerr, 1899). Hence, the gills of adult South American lungfish are short and reduced to a few lobe-like filaments (de Moraes et al., 2005).

Using morphometric measurements to determine the respiratory surface area and thickness of the water-blood barrier of gills, skin and lungs of adult $L$. paradoxa, de Moraes et al. (2005) reported a lower morphometric diffusing capacity in the aquatic gas exchange organs (skin and gill) compared to the lungs, which is in agreement with a higher aerial compared to aquatic (skin+gill) gas exchange in the adult L. paradoxa (Amin-Naves et al., 2004). Based on the skin and gills $\dot{V} O_{2}$ and $\dot{V} \mathrm{CO}_{2}$ obtained in the present study as well as data reported by Bassi et al. (2005) for arterial $\mathrm{O}_{2}$ and $\mathrm{CO}_{2}$ partial pressures at 25 and $35{ }^{\circ} \mathrm{C}$, we estimated values for physiological gas diffusing capacity for cutaneous $\left(\mathrm{D}_{\mathrm{c}} \mathrm{O}_{2}\right.$ or $\left.\mathrm{D}_{\mathrm{c}} \mathrm{CO}_{2}\right)$ and branchial $\left(\mathrm{D}_{\mathrm{b}} \mathrm{O}_{2}\right.$ or $\left.\mathrm{D}_{\mathrm{b}} \mathrm{CO}_{2}\right)$ respiratory organs (Glass, 2010) of L paradoxa. Thus, changes in temperature affected $\mathrm{D}_{\mathrm{c}} \mathrm{O}_{2}$ which decreased to $4.5 \times 10^{-5}\left(20^{\circ} \mathrm{C}\right)$ and increased to $13 \times 10^{-5}\left(35^{\circ} \mathrm{C}\right) \mathrm{ml} \mathrm{STPD} \mathrm{kg}^{-1} \mathrm{~min}^{-1} \mathrm{mmHg}^{-1}$. These values are lower than the cutaneous morphological diffusing capacity previously reported for $\mathrm{O}_{2}\left(94.3 \times 10^{-5} \mathrm{ml}\right.$ STPD kg $\mathrm{min}^{-1} \mathrm{mmHg}^{-1}$; de Moraes et al., 2005). Morphological diffusing capacity values always exceeded the value obtained by physiological methods (Glass, 2010); however, our estimated values for $\mathrm{D}_{\mathrm{b}} \mathrm{O}_{2}$ ranged between $8.9 \times 10^{-5}\left(20^{\circ} \mathrm{C}\right)$ to $12 \times 10^{-5}\left(35^{\circ} \mathrm{C}\right) \mathrm{ml} \mathrm{STPD} \mathrm{kg}{ }^{-1} \mathrm{~min}^{-1} \mathrm{mmHg}^{-1}$, which represent at least sixty times higher values than morphological data $\left(0.15 \times 10^{-5} \mathrm{ml}\right.$ STPD kg ${ }^{-1} \mathrm{~min}^{-1} \mathrm{mmHg}^{-1}$; de Moraes et al., 2005) predicted. This is intriguing, but it has to be taken into consideration that besides numerous capillaries located close to the epithelium of the gill lamellae, gill arches also have numerous capillaries near the epithelium, and their possible respiratory function in aquatic gas exchange cannot be neglected (de Moraes et al., 2005). Another possible explanation for those differences accounts for gas exchange from the head's integument comprising $\sim 10 \%$ of total skin that was included in the anterior chamber of the respirometer, in addition to any gas exchange from the buccal cavity. For $\mathrm{CO}_{2}$, physiological diffusing capacity values estimated for all tested temperatures ranged between $5.1 \times 10^{-4}$ $\left(20^{\circ} \mathrm{C}\right.$ ) to $8.1 \times 10^{-4}\left(35^{\circ} \mathrm{C}\right) \mathrm{ml} \mathrm{STPD} \mathrm{kg}{ }^{-1} \mathrm{~min}^{-1} \mathrm{mmHg}^{-1}$ for skin, and between $4.5 \times 10^{-4}\left(20^{\circ} \mathrm{C}\right)$ to $7.8 \times 10^{-4}\left(35^{\circ} \mathrm{C}\right) \mathrm{ml} \mathrm{STPD} \mathrm{kg}^{-1} \mathrm{~min}^{-}$ ${ }^{1} \mathrm{mmHg}^{-1}$ for gills, which fell below morphological values for either skin $\left(18,000 \mathrm{ml} \mathrm{STPD} \mathrm{kg}{ }^{-1} \mathrm{~min}^{-1} \mathrm{mmHg}^{-1}\right.$ ) or gills (28 $\mathrm{ml} \mathrm{STPD} \mathrm{kg}$ ${ }^{1} \mathrm{~min}^{-1} \mathrm{mmHg}^{-1}$ ) reported by De Moraes and coworkers (2005).

At least for the experimental conditions in the present study, gills exhibited a higher relative contribution than skin for $\mathrm{O}_{2}$-uptake, a pattern that was not affected by acute exposure to $20^{\circ} \mathrm{C}$, but was disrupted once temperature reached $35^{\circ} \mathrm{C}$. Besides having a higher relative contribution at lower temperatures, branchial $\dot{V} O_{2} \mathrm{Q}_{10}$ (1.1) did not follow a typical $\mathrm{Q}_{10}$ effect (i.e. 2.0-3.0) for physiological and biochemical processes (Rome, et al., 1992), while thermal influences on $\dot{V} C O_{2}$ fell within typical $\mathrm{Q}_{10}$ values $\left(\mathrm{Q}_{10}=2.2\right)$. As pointed out by AminNaves et al. (2004), total aquatic $\mathrm{O}_{2}$ uptake (gills and skin) is important at lower temperatures $\left(15^{\circ} \mathrm{C}\right)$ likely because lungs are playing a smaller role, but still higher than aquatic gas exchange, at cooler temperature when they are not solely needed. Metabolic functions are at least partially sufficed by gill ventilation plus any gas exchange occurring through the animals' head/buccal cavity. Furthermore, besides minimal gill surface area (0.0013\%), L. paradoxa exhibits larger numbers of mitochondria and ribosomes in all epithelial cells of the gills, suggesting a highly active metabolism, at least for ion transport (Wright, 1974). A lower morphological diffusing capacity for aquatic organs, less than 1\% (de Moraes, et al., 2005), does not impair arterial $\mathrm{PO}_{2}$ from reaching similar values when aquatic hyperoxia (plus aerial normoxia), or aerial hyperoxia (plus aquatic normoxia) is applied (146 vs. $114 \mathrm{mmHg}$, respectively). Although lung ventilation slightly drops during aerial hyperoxia, it is only during aquatic hyperoxia that $L$. paradoxa markedly reduces lung ventilation (Bassi, et al., 2010).

It is noteworthy that the early literature reported that before the 
breeding season, papillae in the pelvic limb of male L. paradoxa grow into bright-red vascular filaments that persist while the males nurse the eggs and the developing larvae (Kerr, 1899). Although its function remains to be determined, one suggested hypothesis is that the developed filaments during breeding season serves as an auxiliary (or even major) organ for aquatic gas exchange, allowing the male to stay and guard the nest for longer periods without surfacing to breath air (Cunningham and Reid, 1933). This may be an interesting example of a physiological adaption that importantly increases the role of aquatic gas exchange. Development of vascular filaments and their respiratory function remains to be further investigated especially in breeding males.

Acute thermal effects on both cutaneous and branchial $\dot{V} C O_{2}\left(\mathrm{Q}_{10}\right.$ $=2.0$ ) reflects an alternative route for $\mathrm{CO}_{2}$ release when metabolic rate is heat challenged. The relative contribution of skin and gills for $\dot{\mathrm{V}} \mathrm{CO}_{2}$ was not affected by changes in temperature (Fig. 3B), and both contributed about the same for $\mathrm{CO}_{2}$ excretion. Higher capacitance of the water for $\mathrm{CO}_{2}$ relative to $\mathrm{O}_{2}$ (Dejours, 1981; Pittman, 2011) in addition to a large temperature-induced metabolic acidosis (AminNaves et al., 2004; Bassi et al., 2005) contributed to high rates of $\mathrm{CO}_{2}$ excretion and hence to a high aquatic $\dot{V} \mathrm{CO}_{2} / \dot{V} \mathrm{O}_{2}$ relationship observed at all temperatures tested (Fig. 4). In the African lungfish P. aethiopicus an elevated aquatic gas exchange ratio of 5.0 (McMahon, 1970) is similar to values obtained for $L$. paradoxa $\dot{V} \mathrm{CO}_{2} / \dot{V} \mathrm{O}_{2}$ relationship ( 4.0). In contrast, pulmonary gas exchange ratio for $L$. paradoxa exhibits smaller values compared to skin/gills gas exchange ratio (from 0.11 to 0.62; Amin-Naves et al., 2004), showing that more $\mathrm{O}_{2}$ is taken up through the lungs and large amounts of $\mathrm{CO}_{2}$ are excreted by skin/ gills.

L. paradoxa exhibits large increases of pulmonary ventilation when exposed to ambient hypercarbia in the gas phase (Amin-Naves et al., 2007; Sanchez et al., 2005, 2001). Part of that response involves central chemoreceptors since stepwise $\mathrm{pH}$ reductions of the mock cerebrospinal fluid increases the ventilatory response in L. paradoxa (Sanchez et al., 2001; Amin-Naves et al., 2007). In addition to that response, the present study shows that aerial hypercarbia also increases branchial $\mathrm{CO}_{2}$ excretion in this species. Such increase in $\mathrm{CO}_{2}$ excretion through the gills may reflect a compensatory response due to a respiratory acidosis expected to occur during high inspired $\mathrm{CO}_{2}$ through the gas phase with the aquatic gas exchange organs, i.e. gills, playing an important role in $\mathrm{CO}_{2}$ excretion (Perry et al., 2005).

Aerial hypercarbia also reduced branchial $\mathrm{O}_{2}$ uptake in L. paradoxa (Fig. 5). It is not clear why reductions in water oxygen uptake take place when the animal is inspiring hypercapnic gas through their lungs. A possible explanation for that response may involve blood shunting to avoid respiratory branchial arches. In these animals the branchial artery provides a ventral to dorsal shunt in gill arches 3 and 4 that provides an alternative route for blood flow instead of passing through the filaments (branchial shunt) that may reduce the capacity for gas exchange (Laurent et al., 1978; Sandblom and Axelsson, 2011; Morgan and Wright, 1989). In contrast, serial increases in percent aquatic hypercarbia exposure did not affect $f_{G}$ beyond a trend to decrease it once aquatic hypercarbia reached $1 \% \mathrm{CO}_{2}$ (Fig. 6). After that $\mathrm{CO}_{2}$ level, any further increase in aquatic hypercarbia did not further modify $f_{G}$ in our animals. Besides insignificant decreases in $f_{G}$, previous studies have shown that aquatic hypercarbia evokes rises in arterial $\mathrm{PCO}_{2}$ and, consequently, decreases in $\mathrm{pH}$ of $L$. paradoxa as well as increases in pulmonary ventilation (Sanchez et al., 2005). Overall, it seems that exposure to aquatic hypercarbia while animals have access to normocarbic air may induce increases in $\mathrm{CO}_{2}$ loading through animals' aquatic organs surfaces. Previous reports on African lungfish, P. dolloi, have shown a decrease in branchial ventilation that might help to prevent $\mathrm{CO}_{2}$ loading from the environment across their gills. Conversely, an increase in pulmonary ventilation would permit the fish to eliminate the excess $\mathrm{CO}_{2}$ gained through the aquatic route (Perry et al., 2008).

\section{Conclusions}

In conclusion, the relative contribution of each component involved in the aquatic gas exchange, cutaneous and branchial, in L. paradoxa is affected by acute changes in temperature and also hypercarbia. The South American lungfish lives in a seasonally changing environment, inhabiting stagnant and temporary water systems in Central Amazon and Paraná-Paraguay basins in Brazil, and it may undergo considerable temperature oscillations on a daily and seasonal basis affecting aquatic and aerial gas exchange (Chellappa et al., 2005; Amin-Naves et al., 2004). While branchial $\mathrm{O}_{2}$-uptake has a higher relative role at lower temperatures, L. paradoxa lungs are the crucial respiratory organ for supplying metabolic demands, especially at high temperatures (AminNaves, et al., 2004). In contrast, regardless of temperature, both the gills and skin had relatively the same contribution for $\mathrm{CO}_{2}$ unloading across changes in temperature in water.

\section{Acknowledgments}

The present study was supported by Fundação de Amparo à Pesquisa do Estado de São Paulo (FAPESP \#2005/60428-8). G. S. F da Silva currently holds a Young Investigator award grant by FAPESP (\#2013/17606-9 and \#2014/12190-1). We thank Dr. Lynn Hartzler who kindly reviewed our manuscript for English grammar and Dr. Wilfried Klein for valuable suggestions regarding calculations of physiological diffusion capacity. We also thank three anonymous reviewers for their contributions to improvement of this manuscript.

\section{References}

Amin-Naves, J., Giusti, H., Glass, M.L., 2004. Effects of acute temperature changes on aerial and aquatic gas exchange, pulmonary ventilation and blood gas status in the South American lungfish, Lepidosiren paradoxa. Comp. Biochem. Physiol. A Mol. Integr. Physiol. 138, 133-139.

Amin-Naves, J., Giusti, H., Hoffmann, A., Glass, M.L., 2007. Central ventilatory control in the South American lungfish, Lepidosiren paradoxa: contributions of $\mathrm{pH}$ and CO(2). J. Comp. Physiol. B 177, 529-534.

Babiker, M.M., 1979. Respiratory behaviour, oxygen consumption and relative dependence on aerial respiration in the African lungfish (Protopterus annectens, Owen) and an air-breathing teleost (Clarias lazera, C.). Hydrobiologia 65, 177-187.

Bassi, M., Klein, W., Fernandes, M.N., Perry, S.F., Glass, M.L., 2005. Pulmonary oxygen diffusing capacity of the South American lungfish Lepidosiren paradoxa: physiological values by the Bohr method. Physiol. Biochem. Zool. 78, 560-569.

Bassi, M., Giusti, H., da Silva, G.S., Amin-Naves, J., Glass, M.L., 2010. Blood gases and cardiovascular shunt in the South American lungfish (Lepidosiren paradoxa) during normoxia and hyperoxia. Respir. Physiol. Neurobiol. 173, 47-50.

Brinkmann, H., Denk, A., Zitzler, J., Joss, J.J., Meyer, A., 2004a. Complete mitochondrial genome sequences of the South american and the Australian lungfish: testing of the phylogenetic performance of mitochondrial data sets for phylogenetic problems in tetrapod relationships. J. Mol. Evol. 59, 834-848.

Brinkmann, H., Venkatesh, B., Brenner, S., Meyer, A., 2004b. Nuclear protein-coding genes support lungfish and not the coelacanth as the closest living relatives of land vertebrates. Proc. Natl. Acad. Sci. USA. 101, 4900-4905.

Burggren, W.W., Johansen, K., 1986. Circulation and respiration in lungfishes (Dipnoi) In: Bemis, W.E., Burggren, W.W., Kemp, N.E. (Eds.), Biology and Evolution of Lungfishe. Alan R. Liss, New York, 217-236.

Carrol, R.L., 1987. Vertebrate Palaeontology and Evolution first ed.. W. H. Freeman \& Company, New York.

Chellappa, S., Sá-Oliveira, J.C., Chellappa, N.T., 2005. Fish fauna of a temporary lake in an Amazonian conservation area. Acta Limnol. Bras. 17, 283-289.

Cunningham, J.T., Reid, D.M., 1933. Pelvic filaments of Lepidosiren. Nature 131, (913913).

Dejours, P., 1981. Principles of Comparative Respiratory Physiology second ed.. North Holland Publishing, Amsterdam.

Glass, M., 2010. Respiratory function in lungfish (Dipnoi) and a comparison to land vertebrates. In: Jørgensen, J.M., Joss, J. (Eds.), The Biology of Lungfishes. Science Publishers, New Hampshire, 265-282.

Graham, J.B., 1997. Air-Breathing Fishes: Evolution, Diversity and Adaptation first ed.. Academic Press, San Diego.

Harder, V., Souza, R.H.S., Severi, W., Rantin, F.T., Bridges, C.R., 1999. Biology of tropical fishes. In: Val, A.L., Almeida-Val, V.M.F. (Eds.), The South American Lungfish - Adaptations to an Extreme Habitat. INPA, Manaus, 99-110.

Hughes, G.M., 1980. Morphometry of fish gas exchange organs in relation to their respiratory function. In: Ali, M.A. (Ed.), Environmental Physiology of Fishes. Plenum Press, New York, 33-56.

Johansen, K., Lenfant, C., 1967. Respiratory function in the South American lungfish, 
Lepidosiren paradoxa (Fitz). J. Exp. Biol. 46, 205-218.

Johansen, K., Lenfant, C., 1968. Respiration in the African lungfish Protopterus aethiopicus. II. control of breathing. J. Exp. Biol. 49, 453-468.

Johansen, K., Lomholt, J.P., Maloiy, G.M., 1976. Importance of air and water breathing in relation to size of the African lungfish Protopterus amphibius Peters. J. Exp. Biol. 65, 395-399.

Kerr, J., 1899. The external features in the development of Lepidosiren paradoxa. Fitz. Philos. Trans. R. Soc. Lond. B Biol. Sci. 65, 160-161.

Laurent, P., DeLaney, R.G., Fishman, A.P., 1978. The vasculature of the gill in the aquatic and aestivating lungfish (Protopterus aethiopicus). J. Morphol. 156, 173-208.

McMahon, B.R., 1970. The relative efficiency of gaseous exchange across the lungs and gills of an African lungfish, Protopterus aethiopicus. J. Exp. Biol. 52, 1-15.

Meyer, A., Zardoya, R., 2003. Recent advances in the (molecular) phylogeny of vertebrates. Annu. Rev. Ecol. Evol. Syst. 34, 311-338.

de Moraes, M.F., Holler, S., da Costa, O.T., Glass, M.L., Fernandes, M.N., Perry, S.F., 2005. Morphometric comparison of the respiratory organs in the South American lungfish Lepidosiren paradoxa (Dipnoi). Physiol. Biochem. Zool. 78, 546-559.

Morgan, M., Wright, D.E., 1989. Morphology of central compartment and vasculature of the gills of Lepidosiren paradoxa (Fitzinger). J. Fish. Biol. 34, 875-888.

Neiff, J.J., Neiff, A.P., Verón, M.B.C., 2009. The role of vegetated areas on fish assemblage of the Paraná River floodplain: effects of different hydrological conditions. Neotrop. Ichthyol. 7, 39-48.

Perry, S.F., Gilmour, K.M., Swenson, E.R., Vulesevic, B., Chew, S.F., Ip, Y.K., 2005. An investigation of the role of carbonic anhydrase in aquatic and aerial gas transfer in the African lungfish Protopterus dolloi. . J. Exp. Biol. 208, 3805-3815.

Perry, S.F., Euverman, R., Wang, T., Loong, A.M., Chew, S.F., Ip, Y.K., Gilmour, K.M., 2008. Control of breathing in African lungfish (Protopterus dolloi): a comparison of aquatic and cocooned (terrestrialized) animals. Respir. Physiol. Neurobiol. 160, $8-17$.
Pittman, R.N., 2011. Regulation of Tissue Oxygenation - Colloquium Series on Integrated Systems Physiology: From Molecule to Function first ed.. Morgan \& Claypool Publishers, San Rafael.

Rome, L.C., Stevens, E.D., John-Alder, H.B., 1992. The influence of temperature and thermal acclimation on physiological function. In: Feder, M.E., Burggren, W.W (Eds.), Environmental Physiology of the Amphibia. University of Chicago Press, Chicago, 183-205.

Romer, A.S., 1970. The Vertebrate Body first ed.. W.B. Saunders Company, Philadelphia. Sanchez, A.P., Glass, M.L., 2001. Effects of environmental hypercapnia on pulmonary ventilation of the South American lungfish. J. Fish. Biol. 58, 1181-1189.

Sanchez, A.P., Hoffmann, A., Rantin, F.T., Glass, M.L., 2001. Relationship between cerebro-spinal fluid $\mathrm{pH}$ and pulmonary ventilation of the South American lungfish, Lepidosiren paradoxa (Fitz.). . J. Exp. Zool. 290, 421-425.

Sanchez, A.P., Giusti, H., Bassi, M., Glass, M.L., 2005. Acid-base regulation in the South American lungfish Lepidosiren paradoxa: effects of prolonged hypercarbia on blood gases and pulmonary ventilation. . Physiol. Biochem. Zool. 78, 908-915.

Sandblom, E., Axelsson, M., 2011. Autonomic control of circulation in fish: comparative view. Auton. Neurosci. 165, 127-139.

da Silva, G.S.F., Glass, M.L., Branco, L.G.S., 2013. Temperature and respiratory function in ectothermic vertebrates. J. Therm. Biol. 38, 55-63.

Tohyama, Y., Ichimiya, T., Kasama-Yoshida, H., Cao, Y., Hasegawa, M., Kojima, H., Tamai, Y., Kurihara, T., 2000. Phylogenetic relation of lungfish indicated by the amino acid sequence of myelin DM20. Brain Res. Mol. Brain Res. 80, 256-259.

Wright, D.E., 1974. Morphology of the gill epithelium of the lungfish, Lepidosiren paradoxa. Cell Tissue Res. 153, 365-381.

Zardoya, R., Cao, Y., Hasegawa, M., Meyer, A., 1998. Searching for the closest living relative(s) of tetrapods through evolutionary analyses of mitochondrial and nuclear data. Mol. Biol. Evol. 15, 506-517. 